\section{P-193 HOSPICE CNS SEVEN-DAY SERVICE: 6/12 PILOT REVIEW}

Elizabeth Attwood. St Peter's Hospice, Bristol, UK

\subsection{6/bmispcare-2017-hospice.218}

Background The hospice community CNS team has piloted a 9-5 service at weekends and bank holidays in response to national guidance and the need for a continuous seven day service for patients with complex palliative care needs at home (NPEoLC Partnership, 2015-2020).

Aims To promote preferred place of care/death, avoid inappropriate hospital admission, promote appropriate hospice admission and provide continuity of care for hospice community patients.

Methods One CNS working on bank holidays and weekends received 52 urgent referrals from the hospice advice line for interventions associated with uncontrolled symptoms, rapid deterioration, emotional distress, and requests for hospice admission. 47/52 received the service of which 36/47 were visited at home.

Results 1. Promote PPC or PPD

Most patients with complex needs who received this service achieved their preferred place of care, $27 / 32$ or $84 \%$.

2. Avoid inappropriate hospital admission

This was achieved as hospital admission was appropriate for $5 / 5$ or $100 \%$ who were assessed as requiring treatment from secondary care.

3. Access for appropriate hospice admission

Appropriate admission to the hospice was achieved by $10 /$ 12 patients but two were not admitted due to lack of beds. Inappropriate hospice admission was avoided for a further seven patients where $5 / 7$ were supported by this service to stay at home and $2 / 7$ were assessed as requiring hospital admission.

4. Provide continuous care in complexity

CNSs strongly agreed or agreed that the aims of the referral were met for $43 / 44$ or $98 \%$ of patients and families who received this service.

Conclusions The results demonstrate positive outcomes of this service in the urgent management of complex symptoms, distress, deterioration and the promotion of PPC. The service criteria is being expanded to address the unmet need of patients who require proactive CNS interventions to sustain palliative care control and avoid crises.

\section{P-194 REACHING OUT: VOLUNTEER OUTSIDE SERVICE}

Helen Birch, Susan Williams, Karen Groves. Queenscourt Hospice, Southport, UK

\subsection{6/bmjspcare-2017-hospice.219}

Aim Volunteers ensure high quality experience for hospice attendees. Building on existing practice and promoting future excellence, a volunteer workforce was trained to support patients and families in end of life (EoL) choices, in own home/hospital, particularly if alone. Volunteers, aligned to hospice vision and values, complement and 'fill gaps' in existing services.

Approach A review of day/'at home' patients, revealed those 'well enough' for discharge from specialist palliative care (SPC) input, who would still benefit from regular hospice support for self/family. A willing, confident, flexible, health and social care experienced, volunteer team, able to respond to changing demand, recruited to work unsupervised in people's homes. A bespoke training programme, addressed expressed anxieties, role clarity, boundaries and communication skills. Volunteer Outside Service (VOS) co-ordinated by Hospice at Home, ideally placed to promote initiative whilst identifying/ assessing potential patients. Patients seamlessly allocated volunteer visits and SPC as condition dictates. Uniformed volunteers, with lone worker devices, start and finish from hospice, with current patient information to avoid 'surprises' on arrival at patients' home, undertake light household duties; provide listening ear/read; make meals; not expected to undertake personal/clinical care; have clear guidelines to follow if encounter difficulties and appropriately debriefed on return.

Results 10-14 volunteers made 500 home/hospital VOS visits. Volunteers report feeling valued and fulfilled, privileged to be involved in lives of people at an important time and proud of making a difference. Hospice staff report, that despite required time and support, they have integrated well into existing team providing companionship and practical support.

Conclusion Volunteers, integral to package of care, meet complex and challenging patient and family needs. Younger volunteers are needed, due to the demographic profile of the current volunteer workforce. The plan is to support more people dying in hospital and we continue to communicate with secondary care colleagues to ensure professional boundaries are respected. Volunteer training and retention, ensures continuity of a reportedly worthwhile valuable service.

\section{P-195 SUPPORTING PEOPLE AND FAMILIES AT END OF LIFE TO ENSURE THEY ARE CARED FOR IN THEIR PREFERRED PLACE OF CARE}

Alison McCarthy. Greenwich and Bexley Community Hospice, London, UK

\subsection{6/bmjspcare-2017-hospice.220}

The hospice was approached by a Clinical Commissioning Group (CCG) to run a pilot project supporting people in their normal place of residence at end of life.

The CCG felt that too many people were being admitted to hospital and that there were delays in discharge due to lack of co-ordination and personal care.

The aim of this service was to enable people to: die in their preferred place of care; enable rapid discharge from acute care to preferred place of care; avoid unnecessary admission to acute care; provide support to carers/families.

This community service was developed to enhance services already available to support people at end of life.

Method A small team was recruited to deliver this service: one band $6 \mathrm{RN}$ to assess, plan care and co-ordinate the service (Monday to Friday 9 am $-5 \mathrm{pm}$ )

Availability of HCAs to deliver personal care from 8 am- 8 pm, 7 days a week

Referrals were made via the hospice assessment and coordination team.

People were managed by this service for a maximum of 5 days, then discharged on to the most appropriate hospice/ external service for ongoing support

Detailed results were kept and reported on. Results

- 99 people were supported in nine months

- 31 died under the care of the service

- 12 were admitted into the hospice 